Sabrina Moehlecke

\title{
PROPOSTAS DE AÇÕES AFIRMATIVAS NO BRASIL: o acesso da população negra ao ensino superior
}

Dissertação de Mestrado apresentada à Faculdade de Educação da Universidade de São Paulo.

Orientador: Prof. Dr. Romualdo Portela Oliveira

São Paulo 2000 
Universidade de São Paulo

Faculdade de Educação

Programa de Pós-Graduação em Educação

Área de concentração: Estado, Sociedade e Educação

\section{PROPOSTAS DE AÇÕES AFIRMATIVAS NO BRASIL: o acesso da população negra ao ensino superior}

Sabrina Moehlecke

Orientador: Prof. Dr. Romualdo Portela Oliveira

Dissertação apresentada como requisito parcial para a obtenção do título de Mestre em Educação.

Durante a elaboração deste trabalho a autora recebeu apoio financeiro da FAPESP. 
Aos meus pais, Marion e Sérgio,

que me deram a liberdade de seguir minhas próprias opções, e ao Mário, pelo apoio e constante entusiasmo por esse trabalho. 


\section{Agradecimentos}

Não conseguiria reconhecer nem expressar, em tão pouco espaço, toda as contribuições que recebi ao longo desse estudo. Espero que o trabalho aqui desenvolvido e o tempo possam suprir essa restrição. Mas gostaria de deixar meus agradecimentos àqueles que acompanharam essa pesquisa, em seus diversos momentos e às "pessoas" que encontrei nesse início de caminhada.

Ao Mário, pela paciência, carinho e compreensão e também pelas constantes leituras e sugestões.

Aos meus pais, Marion e Sérgio, irmãos, André e Eduardo, e toda família que esteve torcendo por mim. À Anne e todos de São Sebastião do Caí que sempre tão bem me acolheram e proporcionaram ótimos momentos de refúgio.

Ao CEOP - Centro de Educação e Organização Popular, membros, alunos, professores e àqueles que nele acreditaram; um dos responsáveis pelas preocupações que hoje me acompanham nessa dissertação, pelas experiências de vida e formação proporcionada.

Às amigas Cris e Laís, de Campinas, por toda história, amizade e apoio, nos festejos e dificuldades e aos amigos Albetã, Alê, Alessandra, Rogério e demais cruspianos com os quais compartilhei momentos difíceis de esquecer.

Ao CICE - Centro de Estudos de Imaginário, Culturanálise de Grupos e Educação, por me aproximar das inquietações na área da Educação, e especialmente à Profa. Maria do Rosário Silveira Porto e Profa. Maria Cecília Sanchez Teixeira, ao NEV - Núcleo de Estudos da Violência, principalmente aos colegas, pela ousadia e companheirismo diante de novos desafios e ao Grupo de Pesquisa sobre a Trajetória dos alunos da FEUSP, por apresentar e incitar uma nova percepção das possibilidades do trabalho que venho desenvolvendo.

Ao Chico, Daniela, Juca, Lisboa e Marta, da representação discente e pósgraduandos da FEUSP, pelo trabalho conjunto desenvolvido, apesar dos altos e baixos, buscando mostrar que a pós-graduação envolve participação e pela importância dedicada à universidade pública e às questões educacionais. 
Aos colegas de curso e pós-graduação, Batista, Clarice, Diogo, Eliane, Emília, Gladys, Kibe, Liliane, Luís, Marcos e Paula, com os quais pude conversar e trocar idéias.

Ao João, companheiro de empreendimentos, viagens e interesses, e ao Rafael, pelas estimulantes discussões, amizade e pelos documentos e contatos dispostos.

À Prof ${ }^{\mathrm{a}}$ Maria Victória M. Benevides, por proporcionar o primeiro e instigante contato com a discussão sobre ações afirmativas, ainda à época da graduação, pelo interesse em acompanhar as reflexões que desde então tenho realizado, pelo exemplo de pesquisadora, professora e indivíduo e pela minuciosa leitura e pertinentes sugestões no exame de qualificação.

Ao Prof. Antonio Sergio Guimarães, pela orientação nos rascunhos iniciais desse trabalho, ajudando na delimitação da forma como abordar tal tema quando muitas eram as dúvidas, pelas críticas durante o exame de qualificação e pelas reflexões que clarearam minha percepção a respeito.

À Prof ${ }^{\natural}$ Lisete Arelaro, cujas aulas, conversas, idéias e fundamentalmente sua paixão, muito me influenciaram e reafirmaram alguns dos motivos que me trouxeram à área da Educação.

Ao Prof. Celso Beisiegel, pela oportunidade de convívio e trabalho e cujo interesse por essa pesquisa em muito me honra.

Ao Prof. Kabengele Munanga, cujas discussões em classe, trabalho e sensibilidade para romper silêncios há muito enraizados tanto me ensinaram.

Ao Prof. Fábio Leite, pela possibilidade de contato com um mundo riquíssimo e hoje não tão desconhecido.

Também quero agradecer aos militantes e pesquisadores das diversas entidades com quem tive contato, ao material fornecido e àqueles que concordaram em depor, contar suas vidas, posições e idéias: ao Frei Davi, da Educafro, e sua força envolvente; à Cida, Edith, Hédio e Shirley, do CEERT, constantes e importantes referências; ao Hélio Santos, do GTI, e seu carisma e contínua preocupação e empenho na realização de projetos; ao Petrônio, do NCN; à Cidinha, do Geledés; à 
Conceição e Silvana, da APN do Rio de Janeiro; à Marilene, Mayte e Sérgio Martins, do CEAP; à Andrea e Duda, do IERÊ; à Carmem, Sílvio e Valdo, da Steve Biko; ao Marcos, Maria das Graças e Nádia, do Projeto Axé; aos representantes e integrantes dos Conselhos e Secretaria Estaduais da Comunidade Negra da Bahia, São Paulo e Rio de Janeiro.

Ao CIEC - Coordenação Interdisciplinar de Estudos Culturais da Escola de Comunicação da UFRJ e à Graça, pelo material, entrevistas e documentos fornecidos, ao CEAA - Centro de Estudos Afro-Asiáticos, ao CEAO - Centro de Estudos AfroOrientais, aos pesquisadores do Projeto 'Cor e Educação: politicas alternativas de combate à exclusão', e do Projeto 'A Cor da Bahia' e à Beka, do NEV, pelo convívio, empréstimos e amizade.

À secretaria do EDA, principalmente à Solange e Raquel, que sempre me ajudaram, e à Iracema, pela leitura final desse texto.

Finalmente, quero agradecer em especial ao Romualdo, por toda confiança que desde o início depositou em mim e nesse trabalho, incentivando-me de diversas formas e concedendo plena liberdade no desenvolvimento do tema escolhido, e cujas leituras constantes tornaram esse trabalho menos solitário e mais interessante. Reitero, nesse momento, a profunda estima e admiração que lhe tenho. 


\section{Resumo}

A presente pesquisa tem como objetivo realizar um mapeamento da discussão de propostas de ações afirmativas voltadas para a população negra no Brasil. Ainda que incipiente, esse debate já suscita diversas polêmicas e leva a questões sobre o que são essas ações, onde existem, o que propõem e por que. A informação corrente no país traz como principal referência a experiência norte-americana, hoje com quase 40 anos, e identifica as ações, fundamentalmente, com o sistema de cotas, como é o caso de alguns projetos de lei que visam a melhoria do acesso da população negra ao ensino superior. Entretanto, à medida que políticas desse tipo vão sendo mais amplamente discutidas e propostas, torna-se necessário um debate mais detalhado definindo seus limites e possibilidades. Através da análise do processo de denúncia, reconhecimento e, principalmente, das formas de combate ao racismo, observa-se que as particularidades da realidade social, política, econômica e racial brasileiras são apreendidas na formulação de ações afirmativas que vão assumindo significados específicos. 


\begin{abstract}
The current research has as subject mapping the discussion about affirmative actions proposals toward black population in Brazil. Even tough incipient, that debate already raise a roll of controversies and brings questions about what are this actions, where they exist, what they propose and why. The generally information in the country brings the north american experience, today with almost 40 years, as main reference and identify the actions, basically, with the quotas system, like the case of some law projects that aim to improve the access of blacks to higher education. However, as this kind of politics are more widely argued and proposed, a detailed debate becomes necessary to define their limits and possibilities. Analysing the process of denunciation, recognition and, mainly, the forms of combating racism, is observed that the particularities of brazilian's social, political, economical and racial reality are included in the formulation of affirmative actions that are assuming specific meanings.
\end{abstract}




\section{LISTA DE SIGLAS}

APN - Agentes da Pastoral Negros

CDCN/ BA - Conselho de Desenvolvimento da Comunidade Negra do Estado da Bahia

CDCN/ SP - Conselho de Desenvolvimento e Participação da Comunidade Negra do Estado de São Paulo

CEERT - Centro de Estudos das Relações de Trabalho e Desigualdade

CNE - Conselho Nacional de Educação

CUT - Central Única dos Trabalhadores

DCE - Diretório Central de Estudantes

Educafro - Educação e Cidadania de Afro-descendentes e Carentes

ENEM - Exame Nacional do Ensino Médio

FATEC - Faculdades Tecnologia de São Paulo

GTEDEO - Grupo de Trabalho para Eliminação da Discriminação no Emprego e na Ocupação

GTI - Grupo de Trabalho Interministerial

IBGE - Instituto Brasileiro de Geografia e Estatística

ICBSB - Instituto Cultural Beneficente Steve Biko

LDB - Lei de Diretrizes e Bases da Educação Nacional

MEC - Ministério da Educação e Cultura

NCN - Núcleo de Consciência Negra

OIT - Organização Internacional do Trabalho

PCN - Parâmetros Curriculares Nacionais

PNDH - Programa Nacional dos Direitos Humanos

PNLD - Programa Nacional do Livro Didático

PUC - Pontífica Universidade Católica

SECID - Secretaria de Direitos Humanos e Cidadania

SEDEPRON - Secretaria Extraordinária de Defesa e Promoção das Populações Negras

UFBA - Universidade Federal da Bahia

UFRJ - Universidade Federal do Rio de Janeiro

USP - Universidade de São Paulo 
"Se quisermos possuir uma República democrática temos de atribuir ao negro, como indivíduo e coletividade, um estatuto democrático. $\mathrm{O}$ negro tornou-se o teste número um da existência da universalidade e da consistência da democracia no Brasil."

Florestan Fernandes 